\title{
Optimal grip on affordances in architectural design practices: an ethnography
}

\author{
Erik Rietveld $^{1}$ (D) Anne Ardina Brouwers ${ }^{2}$
}

Published online: 5 July 2016

C The Author(s) 2016. This article is published with open access at Springerlink.com

\begin{abstract}
In this article we move beyond the problematic distinction between 'higher' and 'lower' cognition by accounting for so-called 'higher' cognitive capacities in terms of skillful activities in practices, and in terms of the affordances exploited in those practices. Through ethnographic research we aim to further develop the new notion of skilled intentionality by turning to the phenomenon of the tendency towards an optimal grip on a situation in real-life situations in the field of architecture. Tending towards an optimal grip is an inherently affective and dynamic phenomenon. It has been under explored in philosophy, despite its central place in Merleau-Ponty's phenomenology. When the architects experience discontent, attention is typically solicited by the affordances through which possible ways of continuing the improvement of the design can be explored. In various ways this tension or disequilibrium - fueling a tendency towards an optimal grip - is encountered in the complex architectural design practices that we observed. Based on our field material we distinguish between: a) grip in visual perception, b) grip on the design, and c) grip on 'how to design'. The move towards an optimal grip takes shape by joining forces with a landscape of affordances. This landscape includes, for instance, affordances for grasping a cup of coffee, affordances provided by a cardboard model to improve it, as well as for engaging with a person who is not physically present. Because they are skilled, the architects can be responsive to these different affordances in similar ways. Furthermore, in practice the architects are responsive to multiple affordances simultaneously. Through our analysis of the tendency towards an optimal grip we show that our surroundings contribute to skillful action and cognition in a far more complex way than is currently acknowledged in philosophy and cognitive science.
\end{abstract}

Erik Rietveld

d.w.rietveld@amc.uva.nl

1 Department of Philosophy/ILLC/Amsterdam Brain \& Cognition/AMC, University of Amsterdam, Oude Turfmarkt 141, 1012 GC Amsterdam, The Netherlands

2 Academic Medical Center (AMC), University of Amsterdam, Oude Turfmarkt 141, 1012 GC Amsterdam, The Netherlands 
Keywords Philosophy of radical embodied cognitive science $\cdot$ Enaction $\cdot$ Skilled intentionality · Ethnography - Landscape of affordances · Social cognition · Affordances for 'higher' cognition · Tendency towards an optimal grip · Sociomateral practices

\section{Introduction}

It is often assumed that the field of embodied/enactive cognition (Chemero 2009; Thompson 2007) has sensible things to say about so-called 'lower' cognition - e.g. grasping a glass or riding a bike - but not about 'higher' cognition - e.g. designing a building or comforting a friend - (Kirsh 1991; Clark and Toribio 1994; cf. Di Paolo et al. 2010; Clark 2005, p. 236). Architectural design, for example, is traditionally classified as 'higher' cognition because it deals with the immediately present environment as well as the absent, the abstract and the future, for example a vision for a new building.

We believe such a dichotomy between 'lower' and 'higher' cognition is largely artificial and would like to develop a more unified account, which stems from the idea that much of what is pigeonholed as 'lower' cognition or 'higher' cognition, can actually be regarded best as skilled activities that unfold in specific situations. In earlier philosophical work we have emphasized the need for a new conceptual framework. We suggested that by focusing on the notion of Skilled Intentionality in the context of our novel philosophical Skilled Intentionality Framework, we can avoid the problematic dichotomy between 'higher' and 'lower' cognition (Rietveld 2013; Rietveld et al. 2013; Bruineberg and Rietveld 2014, figure 1; Kiverstein and Rietveld 2015; Rietveld et al. forthcoming; cf. Sutton 2007; Geeves et al. 2010; Noë 2012).

In this article, through ethnographic research and philosophical reflection, we aim to develop this new notion of Skilled Intentionality further by turning to the phenomenon of the tendency towards an optimal grip on a situation. We analyze how this tendency takes shape in real-life architectural design practices, precisely because architectural design is a type of activity that is traditionally classified as 'higher cognition'.

Skilled Intentionality is tending towards an optimal grip on a situation by being selectively responsive to multiple available affordances simultaneously (Rietveld et al. 2013; Bruineberg and Rietveld 2014; Schilbach et al. 2013). Ecological psychologist James J. Gibson coined the notion of affordances. Affordances are possibilities for action provided to us by the environment - by the substances, surfaces, objects, and living creatures that surround us (Gibson 1979; Chemero 2003, 2009; Heft 2001). Or, more precisely, an affordance is a relation between an aspect of the (sociomaterial) environment and an ability available in a form of life (Rietveld and Kiverstein 2014). In this paper we will focus on the human form of life or ecological niche. It is the way in which both the sociomaterial environment and abilities are centred in this definition, argued for in Rietveld and Kiverstein (2014), that has allowed us to stretch the standard notion of affordances (Gibson 1979; Chemero 2003, 2009; Heft 2001) so as to include socio-cultural affordances 
for 'higher' cognition, e.g. for making architecture. If one acts skillfully, whether one rides a bicycle or designs a building, one is typically selectively and adequately responsive to affordances (Rietveld 2008a). In concrete situations, skilled activities unfold in relation to a rich manifold of available affordances; i.e. to the landscape of affordances available in a form of life or ecological niche.

To understand the causal processes involved in skilled action, such as the causal role of the brain, one has to understand how neurodynamics, for example, is coupled to the dynamics of the entire brain-body-environment system (Rietveld 2008b). In earlier interdisciplinary work (Bruineberg and Rietveld 2014) that integrates current ideas on self-organization (Tschacher and Haken 2007; Kelso 2012), anticipatory neurodynamics (Friston 2011) and affectivity (Frijda 2007), we sketched how one can understand the causal processes involved in skilled activities from the perspective of self-organization. Lambros Malafouris summarizes this as follows in his work on creativity in the context of craftsmanship in pottery:

"To understand these complex dynamics, we need to rethink what happens in the brain when people are acting creatively in terms of the radical embodied cognitive science that aims to integrate the whole system 'brain-body-landscape of affordances' (Bruineberg and Rietveld 2014; Rietveld and Kiverstein 2014)" (Malafouris forthcoming, p. 6, our italics).

What radical embodied cognitive (neuro)science (Chemero 2009; Dotov 2014; Kiverstein and Miller (2015); Kirchhoff 2015) needs to understand is how the selforganization of this system contributes to the reduction of dis-equilibrium or disattunement between the individual and the dynamically changing landscape of affordances (Bruineberg and Rietveld 2014).

At a different level of analysis, namely that of phenomenology which is our focus here, we have argued that it is a lack of optimal grip on this landscape of affordances that makes particular affordances show up as relevant (Bruineberg and Rietveld 2014; Kiverstein and Rietveld 2015). In line with the distinction between affordances on the one hand, and relevant affordances or solicitations/invitations (Rietveld and Kiverstein 2014; Withagen et al. 2012; Rietveld 2012, 2008a) on the other, we have introduced a distinction between the 'landscape of affordances' and the 'field of relevant affordances', which we abbreviate as the 'field of affordances' (Bruineberg and Rietveld 2014; De Haan et al. 2013). The notion of the landscape of affordances refers to the many affordances that are available in a certain form of life or ecological niche. The best grain of analysis for understanding the landscape of available affordances is the form of life (Rietveld and Kiverstein 2014).

A particular individual is always situated in a particular region of the landscape in a concrete situation, e.g. in a situation at a studio in the socio-cultural practice of architecture. The individual's anticipatory and lived engagement with multiple relevant affordances simultaneously is the relevant level for understanding the notion of the field of affordances. The field of affordances is a field of relevant affordances as lived by a particular individual in a particular situation (for descriptions of this see De Haan et al. 
2013). In other words, it is a field of solicitations. Whereas the landscape of affordances and the ecological niche continue to exist when an individual dies, the existence of someone's field of solicitations is dependent on the life of that particular individual. ${ }^{1}$

To understand Skilled Intentionality it is helpful to investigate further the phenomenon of the tendency towards an optimal grip in concrete situations of skilled activity. This notion of the tendency towards an optimal grip is crucial for understanding Skilled Intentionality and the self-organization of the individual-environment system (Kirchhoff 2015), but unfortunately even its phenomenology has been underexplored in the literature (Rietveld 2012). It is still poorly understood, certainly in cases of what is traditionally called 'higher' cognition, such as for example architectural design practices.

Also underexplored is how we should understand tending towards an optimal grip in cases where we are not just concerned with one thing - e.g. looking at a painting in a museum (Merleau-Ponty 1945/2002) - but have a multiplicity of concerns, as happens in real-life situations - e.g. seeing a painting and feeling concerned about your tired hungry child that walks through the museum with you (Bruineberg \& Rietveld, pp. 1011). Tending towards an optimal grip on this latter more complex situation might mean that one just briefly visits the painting, seeing it adequately but not studying it at length and then moves on to the museum restaurant. This is important because adding context clarifies that in many situations doing something adequately, or in a way that is just good enough, might actually be a consequence of tending towards an optimal grip on the situation as a whole. Given that humans typically care about many things in their relationship to the environment, such more complex situations are not the exception, but the rule. Our concept of a whole field of solicitations reflects this multiplicity. Reallife cases of the tendency towards an optimal grip have been under explored in the literature and our ambition was to collect material in the practice of architecture that would shed a light on this phenomenon.

The notion of the tendency towards an optimal grip (in short: optimal grip) was introduced by Merleau-Ponty (1945/2002) in his Phenomenology of Perception and further developed by Dreyfus amongst others (Dreyfus 2002a, p. 378, b; Dreyfus and Kelly 2007; Thompson 2007; Rietveld 2012; Bruineberg and Rietveld 2014). Dreyfus describes how in skillful activity the situation can simply solicit one to "get into equilibrium with it":

"According to Merleau-Ponty, in absorbed, skillful coping [...] acting is experienced as a steady flow of skillful activity in response to one's sense of the situation. Part of that experience is a sense that when one's situation deviates from some optimal body-environment relationship, one's activity takes one closer to that optimum and thereby relieves the 'tension' of the deviation. One does not

\footnotetext{
${ }^{1}$ The current paper contains primarily third/second person ethnographic observations. So it does not describe engagement with affordances primarily from the first person perspective of the individual's field of affordances, but from an engaged observer's perspective on how the doings of individuals in practice manifest an engagement with the landscape of affordances in which they are situated. The notion of an an 'affordance space' as used by Gallagher and Ransom (forthcoming) also starts from engagement with affordances but does not distinguish explicitly between the field of affordances of a particular individual and the landscape of affordances that is dependent on communal practices of the form of life as a whole (rather than being dependent on the particular individual)..
} 
need to know, nor can one normally express, what that optimum is." (Dreyfus 2002a, p. 378, our italics).

The tendency towards an optimal grip has an experiential aspect: a pre-reflectively experienced tension or harmony, disequilibrium or (temporarily and relative) equilibrium (Rietveld 2008a, 2012). Sub-optimality in the 'person-landscape of affordances' relationship is experienced as a tension, similar to the tension we experience for example when someone stands too close and we are immediately compelled to step back. In various ways this kind of tension which fuels a tendency towards an optimal grip is also encountered in complex architectural design practices. This is what we will explore in this article.

We will see that the concept of the tendency towards an optimal grip is helpful for interpreting ethnographic descriptions of complex situations in the architectural design process. This ethnographic material will show that the architects constantly switch their perspectives on the situation. Such switching has also been described well by architect/ philosopher Juhani Pallasmaa (2009) as "zooming back and forth between various scales and aspects of a project" (2009, pp. 75-76), in order to realize a "harmony" (p. 73) of different elements; to realize a kind of integration that is able to "grasp several points of view" (Pallasmaa 2009, p.18, our italics). So Pallasmaa's descriptions suggest that the (temporarily and relative) equilibrium the architect realizes in the situation gives him or her a grip on the various aspects of the design project. It is this underexplored phenomenon that we would like to investigate in real-life situations.

Furthermore, as we in detail analyze these practices in the context of a real-life architectural project, we will also see that our surroundings contribute to skillful action and cognition in a far more complex way than is generally acknowledged in philosophy and cognitive science.

We draw on extensive ethnographic material that was gathered by one of the authors (A.A.B.) at RAAAF, an Amsterdam based and internationally renowned multidisciplinary studio that makes site-specific work at the crossroads of architecture, art and philosophy. RAAAF makes enactive architecture and art installations in the sense that it takes current insights from radical embodied and enactive cognitive (neuro)science - and the philosophy of affordances that is prominent in that field - as a starting point for its work (see e.g. Rietveld et al. 2015; Rietveld 2016). The studio's full name (Rietveld Architecture-Art-Affordances) reflects this ecological-enactive starting point.

In the period of inquiry, the studio was involved in several projects at the same time. However, one project stood out because of its dimensions and the amount of time the architects RR and AM were spending on it: "Secret Operation 610". In full collaboration with architectural designer FH from Studio Frank Havermans, they were designing a large mobile sculpture to be based at a former Dutch military airbase. Unlike some of the other more conceptual and theoretical RAAAF projects, this project would actually be built during the observation period, making it all the more ideal for purposes of our ethnographic research and offering the best opportunities to explore the tendency towards an optimal grip in its full complexity as characterized so well by Pallasmaa (2009).

The ethnography on which this paper is based was conducted with a strong focus on RAAAF's everyday design practices as they took shape on site in their studio in 
Amsterdam. All people at RAAAF were aware of the fact that AAB was doing participant observation. The aim of the observations was to shed light on the tendency towards an optimal grip in RAAAF's architectural design practices. RAAAF was chosen because it allowed the ethnographer unrestricted access to all situations at the studio and performs at a level that is internationally recognized as state-of-the-art, which is relevant because the aim was to study skilled performances or expertise in action. RAAAF's design approach, characterized by them as 'strategic interventions' (Rietveld et al. 2014, chapter 3) integrates elements at multiple levels of analysis (cf. Pallasmaa 2009), which makes it an excellent field site for studying the tendency towards an optimal grip in all its complexity.

Using the technique of participant observation the architects were followed for a period of 5 months. In line with the methodology of other ethnographic work that investigates sociomaterial practices from a situated, enacted and embodied perspective, such as the work by Annemarie Mol (2002, p. 160), the focus was on "what is being done" in the intertwinement of the material and the social in practice (cf. Orlikowski 2007; Suchman 2007). ${ }^{2}$ (Doing should be understood its broadest sense in our research, so as to include also linguistic acts and non-verbal expression in people's engagements with different aspects of their situations.) Through specific focus on the architects' daily activities as well as all kinds of materials, instruments, techniques, skills and so on involved, it was possible to investigate the knowledge incorporated in situated daily events and design activities. In this way insight of critical detail is gained into how the architects design - in this case - a large mobile sculpture the size of a small house. Note that, as mentioned above, designing a building is traditionally understood as a form of 'higher' cognition.

Working with the material gathered, we will explore how the tendency towards an optimal grip takes shape in practices of architectural design. We demonstrate the architects' way of designing by describing two different episodes of their daily design practices in detail. The two episodes have been singled out because these are rich exemplars of the tendency towards an optimal grip (Part 1) and involve a spatially distant collaborator (Part 2), which makes it a case of what would traditionally have been considered as 'higher' social cognition. First, we are interested in how an adequate grip on the situation was discovered in the design process (cf. Pallasmaa 2009, pp. 18,

\footnotetext{
${ }^{2}$ Mol's work on medical practices illustrates well how the material and the social are intertwined in ways that lead researchers undertaking ethnographic studies to speak of "sociomaterial practices" and to focus on what is being done (Mol 2002; Suchman 2007):

"[T]he practice of diagnosing and treating diseases inevitably requires cooperation. [...] In the consulting room something is done. [...T]wo people are required. A doctor and a patient. [...] The doctor must ask questions and the patient be willing and able to attend to answer them. And in addition to these two people there are other elements that play a more or less important role. The desk, the chairs, the general practitioner, the letter: they all participate in the events [...] As does [the patient's] dog, without whom she might not have even tried to walk more than the $20 \mathrm{~m}$ after which her left leg starts to hurt." (Mol 2002, pp. 22-23).
}

See Rietveld and Kiverstein (2014) for more on the importance of sociomaterial practices for understanding the notion of affordances. 
73; cf. Clark 2005, p. 236). We use the ethnographic material to explore this. The duration of the events described was chosen in view of shedding light on the tendency towards an optimal grip in practice. The project of focus we selected (i.e. Secret Operation 610) constitutes a rather typical example of how things are done and work is approached at the RAAAF studio, with one exception: due to the collaboration with FH and his particular skills, including excellent skills in making 3D-models, more cardboard 3D-models were made than usual. ${ }^{3}$

It is crucial to note that the nature of the research presented in this paper is exploratory. By analyzing the tendency towards an optimal grip as it takes shape in real-life situations we will extend Merleau-Ponty's and Dreyfus' original work on this tendency.

In Part 1 below, we first sketch the context of the architectural design project selected. This description of the context is rather long, because - in line with our ecological and Wittgensteinian philosophical approach - we want to shift the focus away from wondering what goes on in an individual's head, towards the concrete situation and practice in which persons are embedded (Rietveld 2008a; Van Dijk and Withagen 2014). Next we present and analyze the first episode at three grains of analysis on which we identify the move towards an optimal grip. In Part 2 we introduce the second real-life episode, analyze the tendency towards an optimal grip in a complex social situation, and shed light on the complexity involved.

\section{Part 1}

\subsection{Context of the architectural intervention 'Secret Operation 610'}

RAAAF was asked by the two commissioners of Secret Operation 610, art organization SKOR, which promotes art in public places, and the Dutch Province of Utrecht (a regional government), to make an architectural art installation that would allow an initially undefined target group to do research at Shelter 610, a hangar at the vacant airbase that housed US fighter aircraft in the past. The new installation should create a research base for 8-10 researchers. RAAAF was invited, because at the Venice Architecture Biennale 2010 they successfully presented their vision regarding the potential of 10.000 vacant government/public buildings in the Netherlands in a project named Vacant NL (Rietveld et al. 2014, chapter 1). RAAAF's call was to use this sea of vacancy for knowledge development. Central to their approach to the new field of Vacancy Studies was their concept of 'sequential temporariness': being able to move knowledge development activities rapidly from one temporarily vacant location to another. In general RAAAF as a multidisciplinary studio aims to make site-specific architectural art installations that have impact internationally, both in the field of architecture and in the visual arts more broadly. In line with this, Secrete Operation 610 should be both a sculptural artwork, because it would become part of the provincial collection of visual art at the airbase, and a functional research space. Moreover, the

\footnotetext{
${ }^{3}$ It might be informative to note that during the same period at the RAAAF studio, AAB also gathered ethnographic material on the phenomenon of anticipation in the context of four different projects the architects worked on, but a discussion of this will have to wait until another occasion.
} 
commissioners and - at a later stage - journalists and architecture critics would evaluate it on the basis of criteria from both the art world and the practice of architecture.

Due to the fact that the shelter was a cold and humid place most of the year, RAAAF | Studio Frank Havermans decided to make a smaller building inside the large hangar that would allow them to regulate the climate. Moreover, the architects decided to construct the building/sculpture in a way that it could move around at the large airbase, allowing the different scientific researchers to select the places that would be best for their own particular research project. Paradoxically, a few years after the NATO strike fighters left, this vacant airbase was marked to become a national park due to the many protected species living there. Within this new context of the airbase the mobile unit would also create possibilities for innovative research programs that would otherwise be impossible due to the lack of infrastructure. For example, researchers from Delft University of Technology (Aerospace/CleanEra) could use it as a temporary location to develop a program for the environmentally friendly aviation of the twenty-first century known as 'no noise, no carbon, just fly'. The three kilometers long old runway would be the ideal test site for state-of-the-art aviation experiments, according to researchers form Delft's Technical University.

Finding new forms of use for the old runway was important to the architects because they were fascinated by its unique spatial qualities, Cold War atmosphere and cultural history (aviation pioneers such as Anthony Fokker flew their first airplanes here). From the beginning it was clear to the architects that their strategy should be to build a mobile art installation that actually needed this runway in order to avoid that this piece of cultural heritage would be demolished by the regional government to create space for more nature (as was their plan at the time). In addition, being mobile, the sculpture could change its location and be shifted from one vacant space to another at the airbase: Secret Operation 610 embodies 'sequential temporariness', as it were. (For a more detailed description of the architectural intervention see Chapter 3 of Rietveld et al. (2014), RAAAF's book Vacancy Studies on which the above description is based.).

\subsection{Three ways in which the tendency towards an optimal grip takes shape in the design practices of RAAAF}

The first episode that we will focus on in our analysis was observed at the architectural practice of RAAAF in the spring of 2013. Architect / founding partner RR and junior project leader AM were designing the large mobile sculpture. AM has been part of RAAAF's core design team since 2009 and has a large degree of freedom in coming up with draft design proposals. RR and AM form a close team, share many fascinations and do not need many words to interact well, because they are often able to anticipate what the other will do. Their normal, day-to-day mode of interaction is friendly, playful and trusting. When experiencing pressure under tight deadlines their interactions can be more direct and frank, reflecting their mutual focus on the content of their joint project.

The episode at the practice presented below shows how they are designing the rear wheel of the 12.000-kilogram heavy mobile building. Due to an upcoming deadline, there is great pressure to finalize the design of the steel construction, including the part around the wheel. AM has prepared several possible ways to do this. Due to the heavy weight of the sculpture, the construction between the rear wheel and the "tail" of the object has to be very strong. In an earlier stage of the design process they had imagined 
the rear wheel construction to be much smaller than what turns out to be constructively necessary. This creates the concern for the architects that it might become so bulky that it would be out of proportion and too dominant, particularly in respect to its tail and/or when seen from aside. Obviously such concerns regarding the art installation's evocative power need to be balanced with concerns about its constructive solidity and its use (the wheel needs to rotate to allow the sculpture to turn for example). ${ }^{4}$

AM sits at the large worktable/desk behind her desktop as she opens the design program CAD. At a high pace she adapts a 3D drawing, the latest sketch of the mobile sculpture that she is designing together with RR and FH. She clicks on her computer, moving and changing lines, perspectives, colors, and scales; she makes adjustments and new sketches to then again revise these by adjusting lines and so on. Conveying to participant observer $\mathrm{AAB}$ what is special about the design task she is now working on, AM says: "This time it is all about accuracy. Usually in the design process you can always later make adjustments in the design, but now that would be too costly because we work with a steel frame [that will be tailormade for RAAAF]. So, I have to draw the design in great detail in advance". She points out certain aspects of the sketched design: "Like here on the side of this wheel. Look, exactly this point has to carry a lot of weight and also should be able to turn around when the vehicle is driving. The whole design has to be accurate, well thought through and worked out so that those who are going to construct the steel frame know exactly what this part of the sculpture should look like. There is no room for mistakes."

After AM has worked accordingly for several hours, she prints the five designs of the wheel (including the steel construction around it) that were just drawn in 3D. She walks over to RR, puts the printed drawings in front of him on the table when, while keeping their eyes focused on the prints, they pull up their chairs and stoop over the five designs. They study them for several moments with their noses close to the prints. RR picks up a pen, ticks off the second design, and then strikes it through: "This isn't good". He then checks the fifth design: "Can the wheel rotate/turn around here?" "And what about the side-view/profile, what does it look like here?" AM responds in a somewhat doubtful way, after which RR also strikes out this design. "Look, the wheel does not nicely connect here, in the other alternatives you have created more space at this point." He continues: "No. It is clear, this one we reject." AM assents, points out a third design and adds: "Yes, here the connection is better." She draws a connecting line in the design: "And with this attachment the shapes follow up each other more logically." RR follows AM in her views: "How would that part look in the context of the tail and the object as a whole? And this design's side-view, what does that look like?" He gets a transparent piece of paper, places it over the white paper on which the five designs are printed and draws with high pace over the printed 3D drawings. He says he wonders whether or not the adjustments he makes on the transparent paper improve the printed designs, and continues exploring further possibilities by directly drawing on the printed designs or sketching new options next to them. RR raises questions and draws. AM responds, points out to RR certain drawings and details,

\footnotetext{
${ }^{4}$ For understanding the discussion here it might help the reader to see the rear wheel as it has ultimately been constructed (Fig. 3). This wheel can also be seen in motion and in the context of the "tail" of the sculpture in the following video of the finished mobile sculpture: http://www.raaaf.nl/en/projects/739_secret_ operation_610/854
} 
emphasizes points of special interest, and also gets a pen to adjust the drawings that RR is sketching. RR takes this up, and in this way, while raising questions, studying, sketching, making adjustments and so on, they work harmonically.

A couple of days later AM and RR continue their search. They are still not satisfied with the design of the mobile sculpture's rear wheel. They sit next to each other at the table on which, around a desktop and AM's laptop several sketched drawings are strewn, an opened sketchbook filled with notes, a cardboard model, pens, a ruler, glue and so on. RR keeps his eyes focused on the drawings. He puts his finger on one of them and says: "This is too bulky." AM responds by pointing out an alternative, and again, interactively working together, they adjust the drawn design of the rear wheel.

Then, in a firm tone of voice, RR says: "I cannot see it well in this way, I want to see it in 3D. Now it all seems too flat. In 3D the reflection of light is different, but this also changes the experience of the material we will use." AM turns towards the desktop and immediately adapts a 3D-drawn design in the CAD computer program. RR monitors as AM is designing: "Try to enlarge the scale", "Great and now give those various materials different colors", "Hmm, it doesn't really make it much clearer does it?" In a dissatisfied tone RR says that the design of the rear wheel may look good as sketched on paper but observed in its entirety: "The profile isn't clear." For a moment he seems to doubt but concludes then: "I want to see it clearly; perhaps you can quickly make a cardboard version?" AM agrees, shoves aside the on-paper drawn designs, closes the $\mathrm{CAD}$ computer program and starts fabricating the rear wheel in cardboard.

Shortly afterwards AM shows RR the result. RR collects the drawings with which they worked earlier, casts a quick look at them and then holds the cardboard model high up in the air. For a couple of minutes he studies the rear wheel as AM just cut and fabricated it: "Yes, good that you made it again in cardboard, now we can see it better." For a few moments they are both silent, then agreeing that it looks good.

Suddenly, from one moment into the other, they switch their attention to the "next issue"; to another source of discontent with the current state of the design. AM leafs through a pile of drawings while RR starts moving the cardboard model alongside the edge of the table until he seems satisfied with its position. He takes his hands off the model, moves his chair back, stoops forward and examines it with his eyes squeezed. AM follows him in his movement while they discuss several aspects of the sculpture's rear. They are especially interested in the design of its window, which will also function as the vehicle's entry. After they talked briefly AM gets ready to leave for an appointment. RR seems pleased when he quietly expresses his appreciation: "Great, there is development, that's good" (Fig. 1).

In the episode described here, in various ways relative disequilibrium - sub-optimality - is experienced as a tension that fuels the tendency towards an optimal grip. This phenomenon can be found at multiple grains of analysis in the above observations. We limit ourselves to discussing it at three grains of analysis. These are neither exhaustive nor related in static or definite ways; instead together they offer insight into the complexity of this phenomenon.

On a first grain of analysis, in this episode as well as in many other moments when the architects are designing, we can recognize a tendency towards an optimal grip in visual perception as it was described by Merleau-Ponty. According to him: "For each object, as for each picture in an art gallery, there is an optimal distance from which it requires to be seen [...]" (Merleau-Ponty 1945/2002, p. 352). Take for instance the 


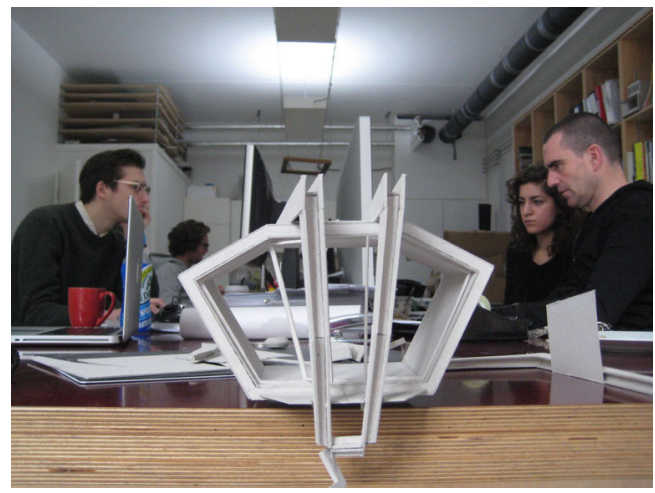

Fig. 1 Rear of a model on the edge of table in RAAAF's studio

point when AM puts five 3D drawings on the table in front of RR. Both keep their eyes focused on the drawings, while they sit down, move their chairs towards the table and bend their heads towards the drawings. They only hold still when their heads are very close to the drawings - the optimal position for that moment. When RR moves the cardboard model around on the table, he lets go of the model when he seems satisfied with its position and immediately starts looking for the best position in relation to the model by moving his chair around and bending forward. When designing the architects often pick up a model, draw or sketch. They sometimes hold a model up in front of them in the air and turn it around while they try out different positions. They move their bodies and aspects of the surroundings such as their chairs in relation to the design as it is made at that moment, and the other way around. They only stop when (sufficient) optimal visibility is achieved; moments at which RR often sighs: "Okay, now I can see it (better)".

In this episode AM and RR search for the 'right' design of the mobile sculpture. Their activities manifest multiple concerns: its wheel has to be constructively sound, functional (e.g. it has to be able to rotate), and the steel volume ('bulkiness') needed to make it strong may not undermine the evocative power of the sculpture as experienced from multiple points of view. The five printed possibilities for improvement of the wheel that AM has drawn on the computer introduce new action possibilities in the current landscape of affordances available in the studio. RR rapidly evaluates the five designs and immediately discards two of them: "This isn't good." Then AM points out a third possibility, adjusts the design by adding a line while she comments that: "Now the design flows more logically." RR responds by posing questions: "What does it look like in its entirety?" And here, at this point, how does it then influence the side-view?" He then draws on a layer of thin transparent paper to explore these questions in a visual way - i.e. "to see it well". Engaged in such interaction and while experiencing discontent (or satisfaction), they experiment and create insight into how to advance the design by exploring multiple ways in which the sculpture's wheel could be made. To see it well seems to mean to be able to anticipate from a multiplicity of perspectives what they would actually be making if they were to build it according to the current design. In other words, to see it well means to understand how a particular aspect of the design (the wheel and the construction around it) will function as part of the sculpture in its various contexts: e.g. in the shelter, on the runway, and seen from all angles. In 
this anticipatory sense the possibilities for action introduced by AM's sketches are also appreciated in the context of the future real-world settings. The way RR sketches on the relevant options anticipates for example the affordances offered by the sculpture (as a whole) in different practices in the future: from press photography to researchers working in the object, to people observing the object moving around the air base during the opening event of the art exhibition. AM and RR come to a harmony when, considered from the multiplicity of perspectives they care about, the design of the wheel is 'right'. To find this kind of satisfactory grip they explore the situation by experimenting with possibly relevant affordances (e.g. the five options and cardboard model made by AM) and anticipating future developments of the design. They explore a whole variety of perspectives on the evolution of the sculpture in its context. In sum, here on a second grain of analysis we can see how the architects move towards an optimal grip on their design step-by-step.

This process of developing a grip on their design has a very important affective dimension, manifested for example in expressions of discontent and signs of tension. Let's take another look at the episode. AM and RR walk through the five possibilities and discuss their discontent with the design as it lies in front of them in the form of 3Ddrawings. In such situations of experienced discontent attention is typically solicited by the affordances through which possible ways of continuing the improvement of the design can be explored or realized. In this episode they (attempt to) do so in various ways, for instance through the canceling of an option and the switching of attention to one of the other design options; the adjusting of connecting lines between various parts and making them follow-up more 'logically'; and through zooming in and out, to test what might prove to be a better design of the wheel. The interaction between their state of discontent and the design as it is created at that very moment takes shape as a continuous adjustment of grip on the situation - from experienced discontent to (adjustment of) the design and back, over and over again.

Such a process of interactions between designers and design situated in a changing landscape of affordances typically lasts until the experienced tension reduces significantly, or even dissolves. Often, as also in the episode above, the architects then 'switch' to a next issue by being responsive to another affordance that solicits attention in that particular situation.

Continuously adjusting their creations the architects seek insight into how they can advance the architectural art installation. They particularly do so through switching between different ways of visualizing the design, thus keeping the design 'moving', as they, repeatedly discontent with a new result, over and over again evaluate the different ways in which the design could be made. This switching is also visible in the episode described above. After spending several days optimizing the sculpture's rear wheel, AM and RR still experience discontent with its design and continue their search. They study the sketched design-possibilities for some moments before RR decides that he has to see the design in 3D: "I cannot see it well in this way, I want to see it in 3D. Now it all seems too flat. In 3D the reflection of light is different, this also changes the experience of the material we will use".

They immediately switch from the design as visualized on paper to the design as visualized in $3 \mathrm{D}$ in the CAD computer program. They typically do so without explicit deliberation about the ways to visualize. The process resembles a kind of situationspecific improvisation in which they "join forces" (Ingold 2013) with the available 
affordances. They experiment by actively manipulating aspects of the design, thus finding out what the design affords (cf. Charbonneau 2013, p. 592) and which of these possibilities they experience as improvements of the overall design. In this manner they explore various adjustments. In the episode we highlight here RR is also unhappy with the $3 \mathrm{D}$ visualization as drawn in the CAD program. He concludes that it doesn't look good and that, in order to get insight into how this detail should be designed, they again need to visualize it differently - this time as a cardboard model.

In such practices of switching between various visualizing forms the design evolves and takes shape. The architects move towards an optimal grip on their design. This, however, does not only involve the final shape of the sculpture's design; it also - on a third grain of analysis - involves moving towards an optimal grip on how they are designing. For example, when the architect experiences discontent with the $3 \mathrm{D}$ visualization made it is another affordance that solicits action: the possibility of making a cardboard model. Crucially, neither the design's final shape nor the ways of designing are pre-given as goals. Along the way, using different design-tools and techniques, the architects improvise and find out how to anticipate the design's evolution in time. The optimal way of designing, then, takes shape in a landscape of affordances that changes gradually over time - moving from a drawing to an over-layed drawing, to a 3-D visualization to a cardboard model and so on. ${ }^{5}$

The phenomenon we encountered at all three grains of analysis is an improvement of grip by the architects through being selectively responsive to the rich landscape of available affordances in concrete situations. Moving towards an optimal grip on the landscape of affordances implies reducing discontent by making use of relevant affordances and one's abilities. In this process of skilled engagement with affordances a (temporary and relative) equilibrium with the situation is (re-)established and the sociomaterial environment of the form of life transformed.

\section{Part 2}

\subsection{The tendency towards an optimal grip on the landscape of affordances in a complex social situation}

The next episode of the architects' everyday design practices that we discuss has been selected because it involves engagement with a spatially distant collaborator, FH. AM has just fabricated in cardboard several designs of the rear window/door through which future users can enter the mobile sculpture. AM places the various possibilities against the rear side of the model. One option after the other, while making pictures of the

\footnotetext{
${ }^{5}$ Note that the events at the third grain of analysis should not be seen as a synthesis of the other two grains of analysis. Rather, we describe and analyze a complex design process from several complementary perspectives (i.e. in this case the three grains). The events at the third grain of analysis unfold on a somewhat longer timescale; it is a grain of analysis at which we can see very well how action switches are related to the development of tension in the person-environment relationship over time. A sketch of this could be as follows: disequilibrium in person-environment system (a lack of grip, possibly experienced as discontent or tension) $\rightarrow$ selective openness to the landscape of available affordances $\rightarrow$ action is solicited by a relevant affordance (e.g. a switch from 3D drawing to making a 3D cardboard model) $\rightarrow$ next person-environment disequilibrium $\rightarrow$ selective openness $\rightarrow$ next action is solicited by a relevant affordance, etc.
} 
results. The pictures are for $\mathrm{FH}$, their collaborator who currently works at another site in the south of the Netherlands, to whom they want to show their improvements. ${ }^{6}$

AM has several cardboard-fabricated rear window models in front of her on the table when she puts down her tools and looks up. She takes her smartphone out of her pocket and positions their latest cardboard model on the edge of the table. She then starts taking pictures of the design, including the various rear window/door options. RR watches intently: "What about holding it a bit more slanted? Yes, like that", "Let's make another one similar to this one here", "And he needs to get an image from this here too." When they examine the just made pictures RR turns out to be dissatisfied with the result: "This connection here cannot be seen well in this picture". AM proposes to revise the picture in Photoshop. RR leafs through the various pictures on AM's smartphone: "Can you show me the other pictures again? Here, the window is closed, it is not completely clear, you can't see what it spatially looks like". He taps a couple of times with his finger on another picture: "It is more beautiful when the window is positioned like here on this one. Yes, here you can clearly see that it spreads out beautifully". AM says she sees what he means and RR concludes in a firm tone of voice: "Okay, let's make a couple more pictures similar to this one".

When they go through the newly made pictures RR says: "Now examine critically; what do we think of the side-view?" AM concisely evaluates the various pictures positively and negatively as she actively leafs through them. Together they consider both the pictures and the model. Then RR sighs: "I find the model exquisite, but I find the view from the side somewhat strange in these pictures". He bends forward to the model and studies its profile: "When I look at it like this I don't have that at all". He then gets a white sheet of paper and holds it behind the model's profile. AM takes another picture which they immediately examine. RR: "Yes, better, now the picture at least reveals what is happening here at the design's side-view." He gathers more white pages and places them around the model. Very precisely he moves the model in relation to this 'white background' as AM again makes another picture of the model. Once more they examine the result and RR nods in a satisfied way: "Yes, exactly, that is what we want to show to FH. Let's send those out" (Fig. 2).

In the following we analyze in greater detail the situation just described in order to deepen insight in the complexity involved in the tendency towards an optimal grip in architectural practices.

This second episode is a complex social situation in which pictures are evaluated that are to be sent to someone who is physically absent. We observe RAAAF's design practice when AM and RR for days have been improving the back of the design, including the rear window/door. They experience tension, yet their discontent is clearly not directed at the emerging shape of the design of the rear because they are quite satisfied with its evocative power (in the cardboard model the window "spreads out beautifully"). In this case their tension is caused by the pictures taken by AM which, as RR experiences, do not demonstrate the improved design accurately enough to $\mathrm{FH}$ who has not yet been able to see the improved cardboard model itself. RR persistently continues the search for a 'çlear' picture that he thinks shows well which adjustments they made to the design: "Yes, exactly, that is what we want to show to FH".

\footnotetext{
${ }^{6}$ Note that "Secret Operation 610 " is a $100 \%$ joint project, which means that all aspects of the design need to be agreed upon by both Studio Frank Havermans and RAAAF.
} 


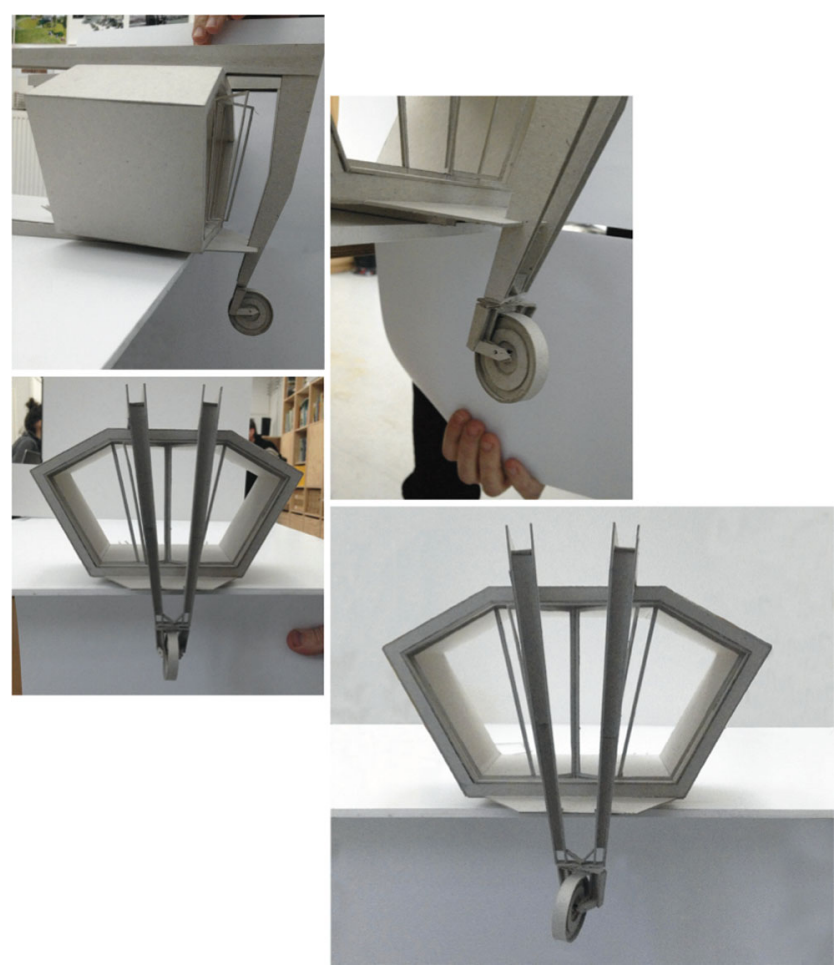

Fig. 2 Photos of rear of model with wheel and window frame, made to be send to spatially distant collaborator FH

FH may be physically absent at that moment and at other times throughout their collaboration, yet at the same time and in various ways, he still takes part in the design practices in which AM and RR engage themselves. They mutually inform each other about their contacts with FH, which frequently take place at FH's studio, on site in Soesterberg and on the phone, and then, typically, discuss FH's feedback and contributions. While working, sketching and drawing together they also often emphasize, through FH or from his perspective, particular points that require special attention, for instance when RR says about a design idea: "This FH would never think up", (smilingly) utters when making an adjustment: "FH will not agree with this one", or while working together with AM on a small particular part of the design notes that for FH it is all about sturdiness: "FH always emphasizes the strength and probably won't mind so much what this detail looks like. But that's a good thing, this way we keep each other sharp".

In the design practices as we observed them, $\mathrm{FH}$ had even when physically absent, an influence on the emerging optimal shape of the design to differing intensities. Such an influence sheds light on the complexity of the situation on which the architects seek a good grip. This situation includes FH even though he is not physically present. In these architectural practices, the tendency towards an optimal grip takes shape as a collaborative effort in which someone who (or something that) is not physically present can nevertheless take part in a process of creation. The architects RR and AM act in relation to a landscape of affordances by being selectively responsive to the many available affordances, 
which includes affordances related to interacting with FH. It is a lack of grip, which is experienced and expressed as tension/dissatisfaction, that makes some of the many available affordances show up as relevant in particular situations. In the episode above coordination with FH can be better or worse. To be able to give feedback from a distance FH needs to see the current model clearly in the pictures. $\mathrm{He}$ also needs time to study the pictures, to make adjustments to the proposed design and to communicate his feedback by email or phone. The architects improve coordination through the actions of updating him about adjustments made and asking him to respond. Interacting adequately with $\mathrm{FH}$ is part of what it takes for RR and AM to get a good grip on this particular situation.

Action possibilities like the possibility to update a colleague on the situation show that getting grip on a landscape of affordances is highly complex. It involves not just seeing something clearly oneself, but also showing something adequately to someone not present on the site. It involves not just optimizing the design in a way RR and AM experience it as better, but also integrating changes proposed by FH (while not increasing their own discontent) or the other way around. Moreover, it involves optimizing the design practices in which they engage themselves by joining forces with the relevant affordances offered by (a.) the multiple material instantiations of the design (sketches, drawings, digital 3D models, cardboard models, steel construction, etc.), (b.) the other(s) at the studio, and (c.) their partner FH.

The relevant affordances responded to are neither just one single affordance nor are they just the affordances of aspects of the environment right before our eyes. Relevant affordances may also include who/what is not physically/materially present in front of our eyes. In these design practices of RR and AM this involves $\mathrm{FH}$, but also the future users of the workspace inside the sculpture; the craftsmen who will make the steel construction of the sculpture; and the location, in particular the runway and the shelter that will be the habitat of this site-specific art installation. ${ }^{7}$

In short: in differing intensities, persons and/or things that are not physically/ materially present on site can still be aspects of the environment that offer possibilities for action (affordances) that the architects are responsive to, and thus be part of the architectural practices in which the design takes shape.

\section{Conclusion}

The concept of Skilled Intentionality, on which we focus in this paper, offers an alternative to current ideas on cognition. We do not classify activities as 'lower' or

\footnotetext{
${ }^{7}$ Note also the example of possibilities for action provided by a blackboard in a classroom. While teaching in a classroom the blackboard behind your back may contribute to/influence your doings. For instance, even though it is not in front of your eyes, the blackboard offers you the affordance to write down the central concepts of your lecture, which you can respond to or not. How the affordances of the unseen blackboard can shape processes and interactions present in the classroom is an interesting open question for empricial research on embodied cogniton. For a first sketch of how this might work please see our discussion of "place affordances" from the perspective of radical embodied cognitive neuroscience (Bruineberg and Rietveld 2014, pp. 3-4, 6).
} 
'higher' cognition. Instead we have moved beyond this dichotomy by approaching all kinds of acting as skilled activities that unfold in particular situations and, related to that, by centering the notion of Skilled Intentionality. Our point is not that it is never helpful to classify activities as 'lower' and 'higher' forms of cognition, but rather that if we want to understand complex human activities such as designing buildings it makes more sense to bracket that dichotomy and simply see the human activity as a form of skilled activity situated in a rich landscape of affordances. We believe that once we take the idea seriously that the landscape of affordances is correlative with the abilities available in a form of life, it opens up new possibilities for tackling the problem that 'higher' cognition has presented to embodied/enactive cognitive science so far. It creates the possibility of accounting for 'higher' cognitive capacities in terms of skillful activities in practices, and in terms of the material resources exploited in those practices. This opens up a need for studying complex skilled activities in relation to the real-life situations in which they take shape, such as our ethnographic study at RAAAF. ${ }^{8}$

Through inquiring into 'the tendency towards an optimal grip on a situation' in real-life we create better insight into Skilled Intentionality (defined as tending towards an optimal grip on a situation by being selectively open and responsive to multiple relevant affordances simultaneously). We have attempted to gain insight into the tendency towards an optimal grip by analyzing how this tendency takes shape in architectural design practices. Based on our field material we distinguish between the move towards optimal grip in visual perception, the move towards optimal grip on the design, and the move towards an optimal way of 'how to design'. The move towards optimal grip is situated as it takes shape in a process of joining forces with a landscape of affordances. The three grains of analysis that we identify then are neither exhaustive nor related in static or definite ways. Sometimes the tendency towards an optimal grip seems to manifest itself solely as a move to perceive something clearly, sometimes we need multiple grains of analysis to do justice to the ways it is manifested.

Tending towards an optimal grip on a situation by being selectively responsive to available affordances is also an inherently affective and dynamic phenomenon (cf. Freeman 2000; Colombetti 2005; Slaby 2008). This is best seen when the architects experience discontent or dissatisfaction. In such situations attention is typically solicited by the relevant affordances through which possible ways of continuing the improvement of the design can be explored. A lack of grip, such as when the architects cannot clearly see how a sketched version would play out in 3D, is lived with an affective tension and invitations by affordances that will increase grip in the particular situation. ${ }^{9}$ Crucially, the soliciting or inviting character of relevant affordances manifests an affective component at the heart of Skilled Intentionality.

\footnotetext{
${ }^{8}$ Interesting discussions of the phenomenon of imagining in the practice of architectural design can be found in Keith Murphy's work (2004, 2005). Recent work by Lambros Malafouris (forthcoming) on pottery takes a similar approach to ours by taking seriously the landscape of affordances.

${ }^{9}$ Note that recent work in the field of ecological psychology has emphasized the importance of such invitations for the theory of affordances (Dotov and Chemero, forthcoming), yet sees them as still ill understood (Withagen et al. 2012). The tendency towards an optimal grip as we have described it does shed light on this.
} 


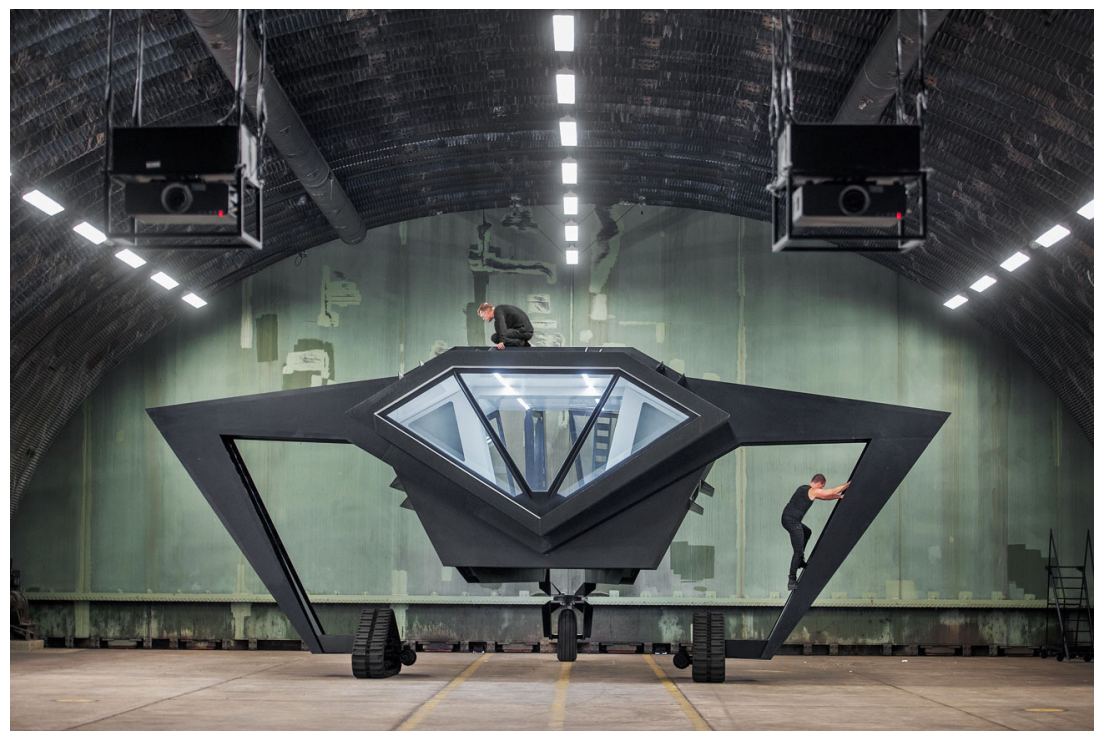

Fig. 3 Press photo of Secret Operation 610 by Raymond Rutting for Volkskrant newspaper

When we analyze the real-life practices in which the architects engage themselves in detail we access a very rich and complex landscape of affordances. Their landscape includes, for instance, affordances for grasping a cup of coffee, affordances provided by a cardboard model to improve it as well as for updating and coordinating with a person who is not physically present. The absent team member affords coordinating with, for example by updating him on adjustments made and asking him for feedback. Because they are skilled and "at home" in their familiar sociomaterial practices, the architects can coordinate with these different affordances in similar ways. A distinction between 'lower' and 'higher' cognitive activities within this skilled responsiveness is artificial. In their practice, in many different ways, architects are responsive to multiple affordances simultaneously. The possibilities of, for example, drinking coffee, making a phone call and solving a complex design problem by creating a model, are all nested in the landscape of affordances encountered in the studio. Skilled Intentionality takes place in engaged interaction with a complex environment: at any moment in time the optimal design of the mobile sculpture develops through the architects' responsiveness to multiple relevant affordances simultaneously. This is also why we need to move beyond the dichotomy between 'lower' and 'higher' cognition, for such classifications do not do justice to the practices in which the architects engage themselves (Fig. 3).

Acknowledgments For feedback on an earlier version of this text we would like to thank Andreas Roepsstorff, Harry Heft, Azille Coetzee, Jelle Bruineberg, Sanneke de Haan, Julian Kiverstein and three anonymous reviewers whose comments have helped us to improve the paper considerably. Without Shaun Gallagher's patience this article would not have been possible. Special thanks to the Frank Havermans and everyone at RAAAF, in particular Ronald Rietveld \& Arna Mackic. Erik Rietveld would like to thank Netherlands Organisation for Scientific Research (NWO) for generous support in the form of a VIDI-grant. 
Open Access This article is distributed under the terms of the Creative Commons Attribution 4.0 International License (http://creativecommons.org/licenses/by/4.0/), which permits unrestricted use, distribution, and reproduction in any medium, provided you give appropriate credit to the original author(s) and the source, provide a link to the Creative Commons license, and indicate if changes were made.

\section{References}

Bruineberg, J., \& Rietveld, E. (2014). Self-organization, free energy minimization, and optimal grip on a field of affordances. Frontiers in Human Neuroscience, 8(599), 1-14.

Charbonneau, M. (2013). The cognitive life of mechanical molecular models. Studies in History and Philosophy of Biological and Biomedical Sciences, 44, 585-594.

Chemero, A. (2003). An outline of a theory of affordances. Ecological Psychology, 15(2), 181-195.

Chemero, A. (2009). Radical embodied cognitive science. Cambridge: MIT Press.

Clark, A. (2005). Beyond the flesh: some lessons from a mole cricket. Artificial Life, 11(1-2), 233-244.

Clark, A., \& Toribio, P. (1994). Doing without representing. Synthese, 101(3), 401-431.

Colombetti, G. (2005). Appraising valence. Journal of Consciousness Studies, 12, 103-126.

De Haan, S., Rietveld, E., Stokhof, M., \& Denys, D. (2013). The phenomenology of deep brain stimulation-induced changes in OCD: an enactive affordance-based model. Frontiers in Human Neuroscience, 7(653), 1-14.

Di Paolo, E.A., Rohde, M., \& De Jaegher, H. (2010). Horizons for the enactive mind: Values, social interaction, and play. In J. Steward, O. Gapenne \& E.A. Di Paolo(Eds.), Enaction: Toward a new paradigm for cognitive science. MIT Press, pp. 33-87.

Dotov, D. G. (2014). Putting reins on the brain. How the body and environment use it. Frontiers in Human Neuroscience, 8(795), 1-12.

Dotov, D.G., \& Chemero, A. (forthcoming). Breaking the perception-action cycle: Experimental phenomenology of non-sense and its implications for theories of perception and movement science. In $\mathrm{M}$. Cappuccio, \& T. Froese (Eds.), Enactive cognition at the edge of sense making: Making sense of nonsense. Houndmills: Palgrave MacMillan.

Dreyfus, H. L. (2002a). Intelligence without representation iMerleau-Ponty (critique of mental representation: the relevance of phenomenology to scientific explanation. Phenomenology and the Cognitive Sciences, 1 , 367-383.

Dreyfus, H. L. (2002b). Refocusing the question: can there be skillful coping without propositional representations or brain representations? Phenomenology and the Cognitive Sciences, 1, 413-425.

Dreyfus, H. L., \& Kelly, S. D. (2007). Heterophenomenology: heavy-handed sleight-of-hand. Phenomenology and the Cognitive Sciences, 6, 45-55.

Freeman, W. J. (2000). How brains make up their minds. New York, NY: Columbia University Press.

Frijda, N. H. (2007). The laws of emotion. Mahwah: Lawrence Erlbaum Associates, Inc.

Friston, K. J. (2011). Embodied inference. In W. Tschacher \& C. Bergomi (Eds.), The implications of embodiment (Cognition and Communication) (pp. 89-125). Exeter: Imprint Academic.

Gallagher, S., \& Ransom, T. (forthcoming). Artifacting minds: Material engagement theory and joint action. In C. Tewes (ed.), Embodiment in evolution and culture. Berlin: De Gruyter.

Geeves, A., McIlwain, D., Sutton, J., \& Christensen, W. (2010). Expanding expertise: investigating a musician's experience of music performance. In W. Christensen, E. Schier, \& J. Sutton (Eds.), ASCS09: Proceedings of the 9th Conference of the Australasian society for cognitive science (pp. 106113). Sydney: Macquarie Centre for Cognitive Science.

Gibson, J. J. (1979). The ecological approach to visual perception. Boston: Houghton Lifflin.

Heft, H. (2001). Ecological psychology in context: James Gibson, Roger Barker, and the Legacy of William James's radical empiricism. Hillsdale: Lawrence Erlbaum Associates.

Ingold, T. (2013). Making: Anthropology, archaeology, art and architecture. New York: Routledge.

Kelso, J. S. (2012). Multistability and metastability: understanding dynamic coordination in the brain. Philosophical Transactions of the Royal Society, B: Biological Sciences, 367(1591), 906-918.

Kirchhoff, M. D. (2015). Experiential fantasies, prediction, and enactive minds. Journal of Consciousness Studies, 22(3-4), 68-92.

Kirsh, D. (1991). Today the earwig, tomorrow man? Artificial Intelligence, 47(1-3), 161-184.

Kiverstein, J., \& Miller, M. (2015). The embodied brain: an argument for radical embodied cognition from neuroscience. Frontiers in Human Neuroscience, 9(237), 1-11.

Kiverstein, J., \& Rietveld, E. (2015). The primacy of skilled intentionality: on Hutto \& Satne's the natural origins of content. Philosophia, 43(3), 701-721. 
Malafouris, L. (forthcoming). Creative thinging: the feeling of and for clay. Pragmatics \& Cognition. Merleau-Ponty, M. (1945/2002). Phenomenology of perception, trans. C. Smith. Routledge.

Mol, A. (2002). The body multiple: Ontology in medical practice. Durham: Duke University Press.

Murphy, K. M. (2004). Imagination as joint activity: the case of architectural interaction. Mind, Culture, and Activity, 11(4), 267-278.

Murphy, K. M. (2005). Collaborative imagining: the interactive use of gestures, talk, and graphic representation in architectural practice. Semiotica, 156(1), 113-145.

Noë, A. (2012). Varieties of presence. Harvard University Press.

Orlikowski, W. J. (2007). Sociomaterial practices: exploring technology at work. Organization Studies, 28(09), 1435-1448.

Pallasmaa, J. (2009). The thinking hand: Existential and embodied wisdom in architecture. Chichester: Wiley.

Rietveld, E. (2008a). Situated normativity: the normative aspect of embodied cognition in unreflective action. Mind, 117(468), 973-1001.

Rietveld, E. (2008b). The skillful body as a concernful system of possible actions: phenomena and neurodynamics. Theory \& Psychology, 18(3), 341-363.

Rietveld, E. (2012). Bodily intentionality and social affordances in context. In F. Paglieri (Ed.), Consciousness in interaction. The role of the natural and social context in shaping consciousness (pp. 207-226). Amsterdam: J. Benjamins.

Rietveld, E. (2013). Skilled intentionality for 'higher' cognition. unpublished lecture at conference. The reach of REC, Antwerp, June 18th 2013.

Rietveld, E. (2016). Situating the embodied mind in landscape of standing affordances for living without chairs: materializing a philosophical worldview. The Journal of Sports Medicine. doi:10.1007/s40279016-0520-2.

Rietveld, E., \& Kiverstein, J. (2014). A rich landscape of affordances. Ecological Psychology, 26(4), 325-352.

Rietveld, E., De Haan, S., \& Denys, D. (2013). Social affordances in context: what is it that we are bodily responsive to? Behavioral and Brain Sciences, 36(4), 436.

Rietveld, R., Rietveld, E., Zoeteman, M., \& Mackic, A. (eds.) (2014). Vacancy studies: Experiments \& strategic interventions in architecture. Rotterdam: nai010 Publishers.

Rietveld, E., Rietveld, R., Mackic, A., Van Waalwijk van Doorn, E., \& Bervoets, B. (2015). The end of sitting: towards a landscape of standing affordances. Harvard Design Magazine, 40, 180-181.

Rietveld, E., Denys, D., \& Van Westen, M. (forthcoming). The skilled intentionality framework for embodied/ enactive cognitive science. In Newman et al. (Eds.), Oxford handbook for embodied cognitive science. Oxford: Oxford University Press.

Schilbach, L., Timmermans, B., Reddy, V., Costall, A., Bente, G., Schlicht, T., \& Vogeley, K. (2013). Toward a second person neuroscience. BBS, Behavioral and Brain Sciences.

Slaby, J. (2008). Affective intentionality and the feeling body. Phenomenology and the Cognitive Sciences, 7 , 429-442.

Suchman, L. A. (2007). Human-machine reconfigurations: Plans and situated actions. Cambridge: Cambridge University Press.

Sutton, J. (2007). Batting, habit and memory: the embodied mind and the nature of skill. Sport in Society, $10(5), 762-786$.

Thompson, E. (2007). Mind in life: Biology, phenomenology, and the sciences of mind. Cambridge: The Belknap Press of Harvard University Press.

Tschacher, W., \& Haken, H. (2007). Intentionality in non-equilibrium systems? The functional aspects of selforganized pattern formation. New Ideas in Psychology, 25(1), 1-15.

Van Dijk, L., \& Withagen, R. G. (2014). The horizontal worldview: a Wittgensteinian attitude towards scientific psychology. Theory \& Psychology, 24(1), 3-18.

Withagen, R., De Poel, H., Araujo, D., \& Pepping, G.-J. (2012). Affordances can invite behavior: reconsidering the relationship between affordances and agency. New Ideas in Psychology, 30, 250-258. 